\title{
Analysis of Impact of Female Education and Labour Force Participation on Disparities in Under-Five Mortality Rate among Selected African Countries
}

\author{
Priscilla Adomako Gyasi* $\quad$ Yinghua Chen Linda Hyde-Quartey Sabina Ampon-Wireko \\ Department of Public Administration, School of Management, Jiangsu University301, \\ Xuefu Road. Zhenjiang, P. R. China
}

\begin{abstract}
The role of female education is crucial for the development of any country, especially for the third-world countries. The objective of this paper is to analyze the impact of female education and female labour force participation disparities serving as key influential factors of under-five mortality among some selected developing countries in Africa. Annual panel data sets of the selected countries from the year 2000 to 2017 were used for the study. The panel random effect model was used to estimate the polled data for the selected countries. Moreover, the time series multiple regression analysis was used to estimate the predictors of the disparities of under-five mortalities in the individual countries. The study also examined the major causes of the disparities in under-five mortality among the selected countries by emphasizing on female education as major predator of the disparities inter-alia some key control variables such as gross domestic product(GDP) per capita, educational expenditure, female labour force participation, and gross fixed capital. The paper concludes that female primary school enrolment and labour force participation are statistically significant and predominately strong predators of the disparities in the rate of under-five mortality among the selected countries. The study further recommends that health policies to reduce child mortality should be designed inter-alia with educational policies since education makes an individual more conscious about their health.
\end{abstract}

Keywords: Female education; Under-five mortality; Female labour force participation, Education expenditure, Economic growth, Panel analysis.

DOI: $10.7176 / \mathrm{PPAR} / 9-3-14$

Publication date:March $31^{\text {st }} 2019$

\section{Introduction}

Globally, child death has remained a major health challenge in spite of the remarkable efforts made to improve the survival rate of children particularly under-five children. It has been established that, two global zones south Asia and Africa constitute $80 \%$ share of global Child death as the former takes $30 \%$ and the later region commands 50\% respectively (Unicef, 2018). Africa continues to record high incidence of under-five mortality and child death, irrespective of the efforts made by various government in Africa with the aim of reaching the millennium development agenda (Bhutta et al., 2010). For instance in 2017, approximately 5.4 million deaths were recorded among children under five years worldwide while about $50 \%$ of these child deaths occurred in Africa (Unicef, 2018). This has created a lot of fear and panic burdening policy makers, mothers, and parents among other stakeholders. Furthermore, this has attracted several researchers from all parts of the World to conduct advanced studies to improve child survival especially in Africa for the next decades. Previous studies have indicated that, as high as child population continue to occur in Africa which is a comfort zone for High Child mortality, an estimated proportion of $60 \%$ of global under-five child deaths will occur in the next decades if sustainable measures are not taken. There is still disparities among the African countries classified as the highest in terms of child mortality in the world. This is partly attributed to difference in economic growth, educational attainment, literacy rates and health expenditure policies in these countries (Braveman et al., 2005). The wide spread of disparities in these indicators cannot be over emphasized in organizing converted actions to improve child survival. Researches have revealed that the risk for a child to die in a poor country is 14 times higher than a child in a high income country (Braveman et al., 2005; Wagstaff et al., 2004). It is evident that an alarming disparities in under-five mortality rates within countries could be attributed to the mother's education. (Wagstaff et al., 2004) opine that, children born to uneducated mothers have a higher risk of dying than their counterparts born to educated mothers and this dispraise also widens as mothers become poor. Under-five mortality is seen to be a more common phenomenon among poor households than rich families. Income inequalities has been cited as one of the major underlying factor contributing to under-five mortality particularly in Africa.

Several scholars who have studied the under-five mortality among African countries have focused on the occurrence and their causes while placing less emphasis on the major effect of some regional and socioeconomic disparities among countries in terms of income distribution, educational attainment, labour force participation and educational policies. Previous studies have shed light on the significance of giving education 
to females particularly the spillovers achieved which contribute to the socioeconomic development of our societies. Scholars maintain that, increasing female education helps to improve the health of their children and the total wellbeing of the family. Educated women are more conscious about the health of their family especially children and therefore keep practice of at least some basic health tips to improve their health standard. Educated women tend to have positive attitude towards family planning methods and develop the habit to adopt it to control births. According to (Abu-Ghaida \& Klasen, 2004), education of women contribute significantly to improving the well-being of individuals and keep the fertility rate among females low which helps in a sustainable socio-economic and living standards of societies.

These extant studies have shown that, educating the women is crucial as it contributes positively and significantly to increasing their income earning capacities, labour force participation and the nutrition of their children. Educated mothers have the financial abilities to meet the basic nutritional diet requirement of their children and helps to minimize their risk of dying or becoming malnourished (Abu-Ghaida \& Klasen, 2004). It has been argued that, educated mothers have more access to antenatal, neonatal and post natal cares than their less educated counterparts which puts the educated mothers at a lower risk of losing their babies compared to the less educated.

This presents a major weakness of the previous studies while this study fills the research gaps by addressing these key issues which has been neglected in previous research. This study is among the pioneering studies to consider female labour force participation disparities, female education disparities, and national income disparities serving as key influential factors of under-five mortality among selected developing countries specifically in Africa where under-five mortality presence is highest across the globe. The outcome of this study would provide adequate information to inform policy makers, political leaders and other stakeholders in the African countries on how crucial female education is needed in achieving a sustainable socioeconomic development. This would provide the basis for policy direction on the essence to prioritize female education with high political will and commitment especially towards accomplishing low child death and moving Africa from our global top position as a leading continent in child death. This paper builds a strong argument that, health policies to reduce child mortality should be designed inter-alia educational policies since education makes individual more conscious about their health thus a healthy mind is a sound mind for learning and also that policies to solve child mortality should prioritize female education and labour force participation. This study also contributes to the limited literature on how disparities in labour force participation among women contribute to child mortality in less developed economies while serving as a springboard for future researchers.

\section{Understanding the Significance of Female Education in Socio-economic Development}

Female education is a master-key to economic growth and development. Among the works of schooling variable was positive and highly important to economic growth and development, and countries can grow faster by 0.2 percent points per year (El Alaoui, 2015). Recent works and surveys reveal that educating females brings short term and long term benefits including family health improvement, low infant mortality rates, higher family wage-earning rate, family intellectual development and more. Similar results are found by numerous authors such as (Ashraf, Weil, \& Wilde, 2013). Female education plays a role in economic growth and benefit the society and individual as well. For individuals, education increases employment opportunities and income and improve life quality. By means of investing on females' education, the position of females in economic, social, cultural and political life increases. It is widely known that education enhances labour market productivity and income growth but educating females also has beneficial effects on measures of social well-being not measured by the market. Rising levels of education improve females' productivity in the home which intern can increase family, health, child survival, and investment in children human capital. Therefore, female education has a huge impact on all of society. According to numerous studies such as (Bloom, Canning, \& Chan, 2006; Klasen, 2002) female education and economic growth have positive and long-run relationship. Education continue to be a key of growth and development of a country as well as a major factor in the reduction of poverty and migration, and also improvement in the quality of institutions and social conditions of citizens. Studying and measuring the impact of females' education on economic growth is always important, especially, in developing countries where the school enrolment remains low, mainly for females and in rural area.

According to (Office \& Vietnam, 1999) poor countries differs from rich countries not only because of capital but for the reason of having less knowledge. World Bank illustrated with a case study between Ghana and the Republic of Korea. In its report, both countries had the same per capita income in 1958, but Korea's per capita income was six times better than that of Ghana's in the end of the 90's. The results showed that half of gap is anticipated by Korea's greater success in acquiring knowledge and using it. This illustration clearly shows that there is a positive correlation between education and economic performance. Knowledge is regarded a driver of growth in the context of globalization and the revolution of technology. The World Bank also asserted that acquiring knowledge involves a universal basic education assurance. Major emphasis were made on extending education to females and other disadvantaged groups so as to create the opportunities of lifelong learning and 
also supporting tertiary education especially in the sciences and engineering. Not to mention that countries without a minimum technological and scientific capacity will be behind in realizing human and social benefits such as improved health, nutrition, rising life expectancy, lower infant mortality and sanitation (Klasen, 2002). Numerous works including (Bloom et al., 2006) have indicated that female education has a positive direct and indirect contribution to the economic growth of a country. Universally, economic growth is referred to as the increase in the volume of goods and services a country produce over a period of time and it is measure by GDP. Economic growth includes the combination of various type of capitals such as human, natural and produced capital to produce goods and services. Greater investments in female education could yield to a 'growth premium' that raises per capita income by about 0.2 percent in these countries. To say, he affirms that female education affect economic growth and also can improve household welfare. Again, female education supports macroeconomic growth through higher females labour force participation, stronger human capital and high productivity. (Shirahase, 2000) aimed to investigate the relation of educating female and fertility rate. They revealed that educating females plays a major role in the reduction of fertility rate and hence suggested governments should pay much attention to both female and male education so as to reduce the level of fertility rate. (Mujahid \& uz Zafar, 2012) attempted to examine the connection between female labour participation and economic growth. Their results disclosed there is a relationship between female labour participation and economic growth and that education and economic activities result in labour force participation and improvement of economic growth.

Barro analyzed the effect of education on the economic growth in a panel of about 100 countries which was observed from the period of 1965 to the period of 1995. This study pinpoint on the importance of knowledge spill over. In the study, school attainment of females at secondary and higher levels has not affected economic growth because in the labour market highly educated females are not well utilized. However, the work of (Barro \& Lee, 2010) confirmed that education of workers has a significant positive effect on per capita income of a country. Similar results are found in his work (Barro \& Lee, 2013). He demonstrate that quantity and quality of schooling both matter to economic growth but the quality of education is more important. (Gava \& Duada, 2013)investigated that female education results in economic growth in Nigeria during the time frame of 1975 to 2008. The findings were that there is a long-run relationship between female education and economic growth and that education has an impact on economic growth of Nigeria. The recommendation of this study was that much attention should be given to policies relating to educational system, female enrolment and female contribution to economic growth. (Ainsworth, Beegle, \& Nyamete, 1996) also examined the relationship between female education and economic growth.

\section{Methodology}

This section describes the research designs, type of data, sources of data, variables to be used, model for data analysis, feasibility and data stability analysis, and diagnostic checks. The study seeks to examine the impact of female education and labour force participation on disparities in under-five mortality rate among selected African countries. The main thrust and direction of this study present a unique approach to reexamine this problem by shedding more light on the mechanism through which female education influence socio-economic development of these countries. This paper employs the quantitative research design in a novel statistical computation approach. With this quantitative research design, various hypotheses will be test to establish relationships between variables.

\subsection{Sources of Data}

Annual panel data sets covering a period of 2000-2017 were used for the study. This annual panel data sets were organized from the World Bank's World Development Indicators (WDI) online database for nine major African countries purposively based on data viability, unique educational policies, and widely reported literature on the issues of under-five mortality and income inequalities. These countries are highlighted in red color and include Egypt, Tunisia, South Africa, Burkina Faso, Ghana, Cameroon, Ethiopia, Central African Republic, and Kenya as shown in Figure 1. 


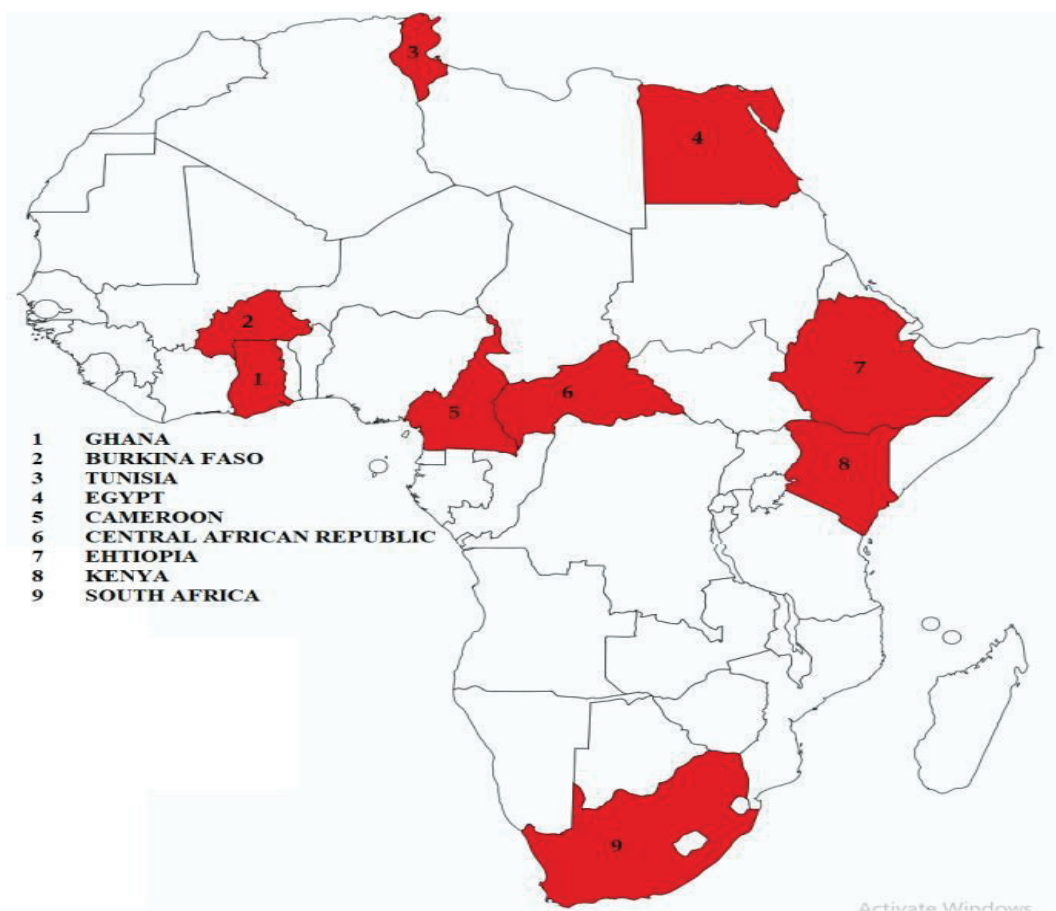

Figure 1. African map showing locations of the study

The numbers in the map and the locations represent the countries whose data were used for the study. Thus: 1.Ghana 2. Burkina Faso, 3.Tunisia 4. Egypt, 5.Cameroon 6. Central African Republic 7. Ethiopia 8. Kenya 9. South Africa. These countries have different growth rates, gender inequalities, educational histories, and diverse socio-cultural backgrounds.

\subsection{Data and Measurement of Variables}

\subsubsection{Under-Five Mortality}

Under-Five mortality was measured as the number of children who die before attaining 60 months. This is usually used as an indicator of children's population welfare and the efficiency of public health policies in the country. The time series patterns of the under-five mortality from 2000-2017 have been presented in the Figure 2 below with Ethiopia recording the highest deaths.

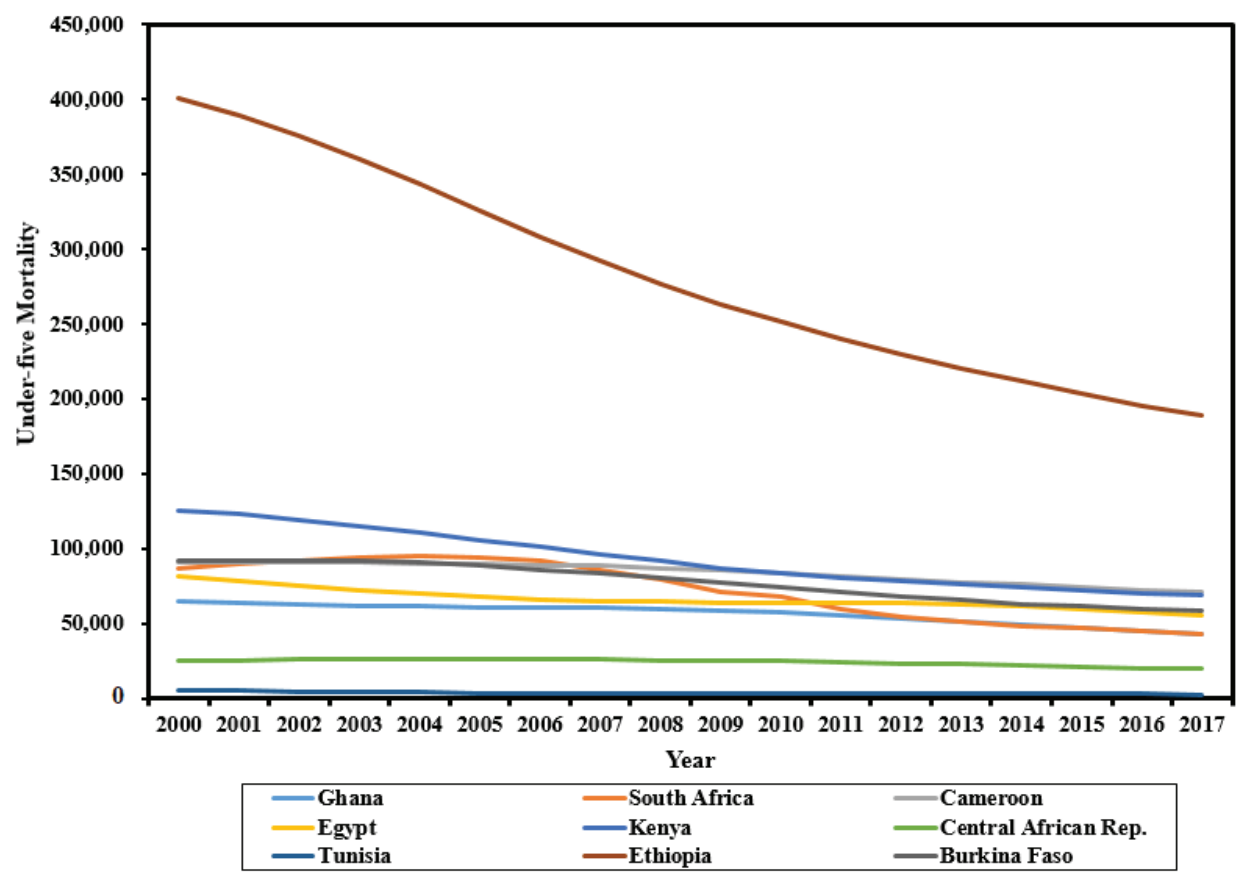

Figure 2. Time series patterns of under-five mortality 


\subsubsection{Female Primary School Enrolment}

This was measured as the percentage of the total enrolment in primary schools. This measures how gender equality in education is considered in educational policies and socio- economic development of the countries. The time series patterns of the female primary school enrollment from 2000-2017 have been presented in the Figure 3.
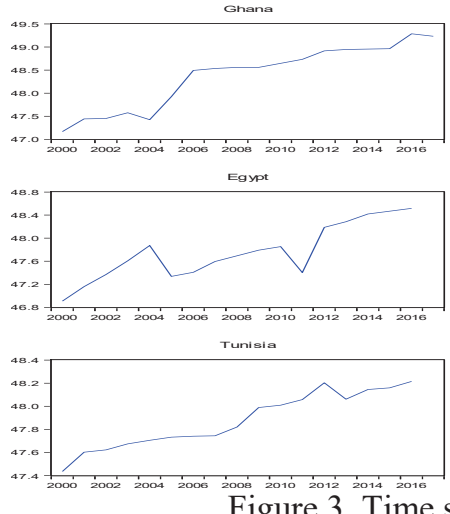
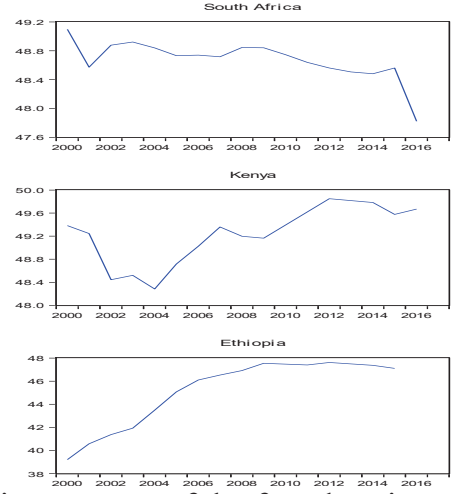

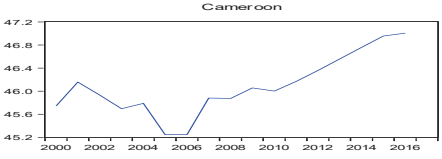

Central African Rep
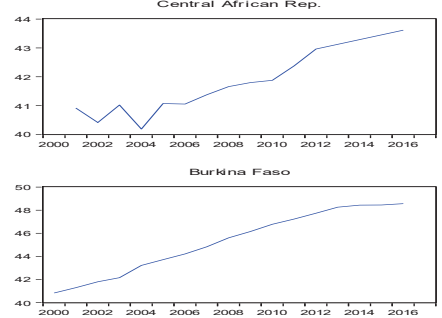

Figure 3. Time series patterns of the female primary school enrollment

3.2.3 Female Secondary School Enrolment

This was measured as the percentage of the total enrolment in secondary schools. This measures the level of skilled labour in the country and at times the quality of human labour in the country. Female education is expected to reduce Under-five mortality among these countries (Wagstaff et al., 2004) . The time series patterns of the female secondary school enrollment from 2000-2017 have been presented in the Figure 4.
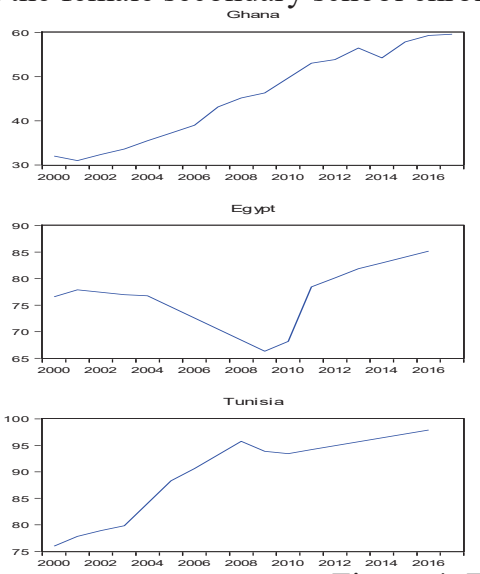

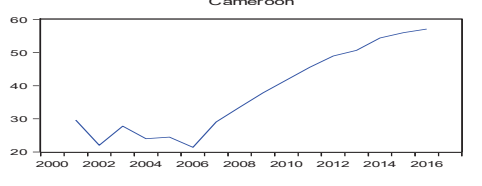

Central African Rep
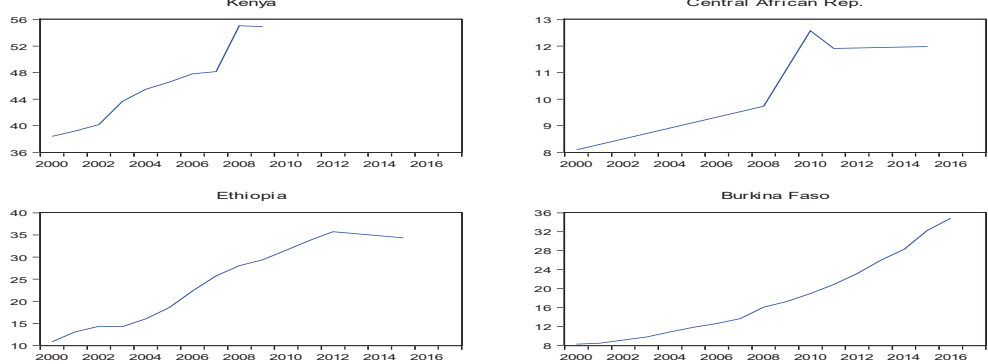

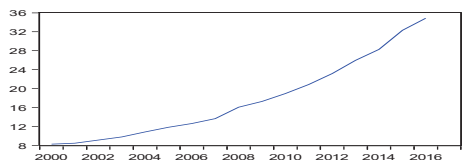

\subsubsection{Gross Domestic Product Per Capita}

GDP per capita is gross domestic product divided by mid-year population. GDP is the sum of gross value added by all resident producers in the economy plus any product taxes and minus any subsidies not included in the value of the products. It is calculated without making deductions for depreciation of fabricated assets or for depletion and degradation of natural resources. Data are in constant 2010 U.S. dollars. The GDP per capita is mostly used to determine the standard of living of a country and the ability of the individual's citizens to obtain a good health care. This per capita income also helps the governed to provide necessary health system for the people and it is expected to reduce under-five mortality(Braveman et al., 2005). 


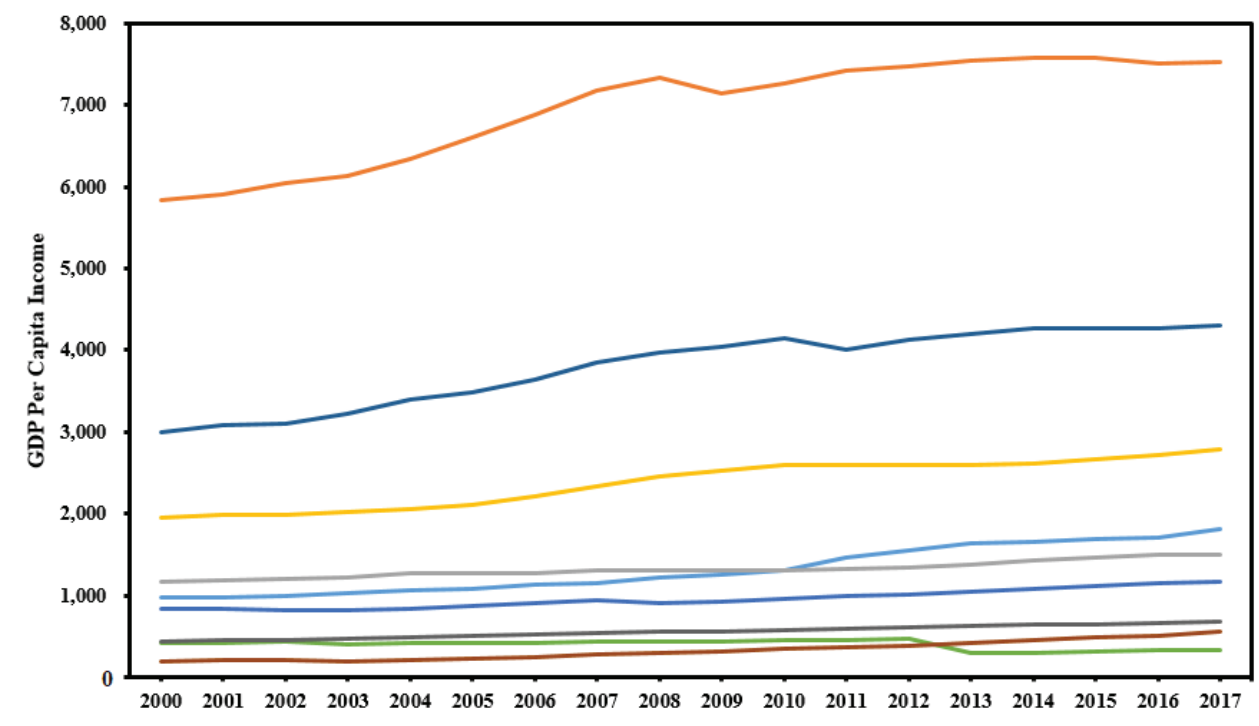

Year

\subsubsection{Labour Force Participation}

\begin{tabular}{|c|c|c|}
\hline $\begin{array}{l}\text {-Ghana } \\
\text {-Egypt }\end{array}$ & $\begin{array}{l}\text {-South Africa } \\
\text { - Kenya }\end{array}$ & $\begin{array}{l}\text { - Cameroon } \\
\text { —Central African Rep. }\end{array}$ \\
\hline
\end{tabular}

Figure 5. Time series patterns of GDP Per capita income

The Labor force participation rate of females were measured as the percentage of female population ages 15-64 who are in the active labour force as modeled ILO estimate. Labor force participation rate is the proportion of the population ages 15-64 that is economically active: all people who supply labor for the production of goods and services during a specified period. Figure 6.0 below depicts the female Labourforce participation among the countries studied.

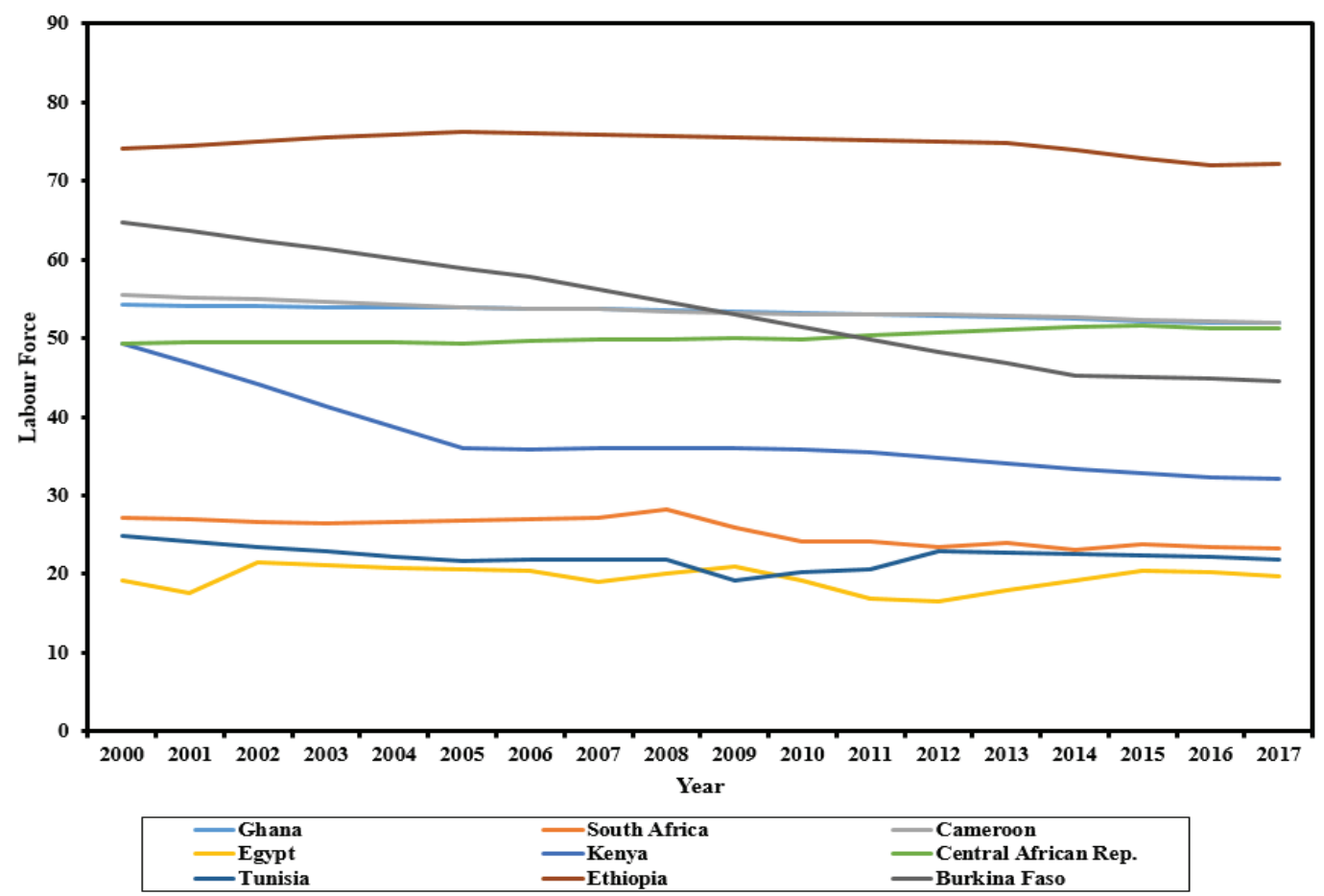

Figure 6. Female labour force participation

\subsection{Estimation Technique}

Estimating panel data generally involves three main models to analyze panel data namely: Fixed and Random effect models and the OLS. These three models were employed to examine the effect of female education on the disparities of under-five mortality. Fixed effect (FE) model is mostly applied and yield a consistent estimates when cross-country heterogeneity or differences across the observed countries are assumed to be correlated with 
their explanatory variables used in the estimation model. However, the random effect (RE) model relaxes this assumption but produces more efficient estimates too if there exist a country specific time invariant variables which are key variables accountable for the changes in the dependent variables. The fixed effect model specified as:

$$
\begin{aligned}
& Y_{i t}=\alpha_{i}+\beta X_{i t}+v_{i t} \\
& v_{i t}=\alpha_{i}+v_{i t}
\end{aligned}
$$

Where $Y_{i t}$ denotes the dependent variable, $\beta$ represents the coefficient of the independent variable, $X$ represents, the explanatory or independent variables, $t$ is the time period, $\alpha_{i}$ represents a cross section-specific effect and that of $v_{i t}$ denotes the error term. The random effect model is also given as:

$$
\begin{aligned}
& Y_{i t}=\beta X_{i t}+u_{i t} \\
& u_{i t}=\alpha_{i}+v_{i t}
\end{aligned}
$$

Regarding the nature of the countries selected from different regions with different history, resources, colonization, growth rates, gender inequality issues, and other economic fundamentals, using the two models become necessary. The Hausman test was organized to test the most effective estimate between FE and RE. The results show that the RE estimates were appropriate however, the results from both are presented in the table. Again, the OLS was used to estimate the impact of the female education among other independent variables on disparities of under-five mortalities in the individual countries following the time series data approach. The $\mathrm{R}^{2}$, P-values. F-statistics and the t-values were used to judge the explanatory power and the significant level of the variables the coefficient for both the OLS, and the RE models discussed below. Based on this, the estimated panel regression model is given as

$$
\begin{aligned}
& U M R 5_{i t}=\beta_{0}+\beta_{1} \text { lnEduexp }_{i t}+\beta_{2} \text { lnprim }_{i t}+\beta_{3} \text { lnSec }_{i t}+ \\
& \beta_{4} \ln G d p / \text { capita }_{i t}+\beta_{5} \text { labourforce }_{i t}+\beta_{6} g f c_{i t}+\varepsilon_{i t} \\
& \ln U M R 5_{t}=\beta_{0}+\beta_{1} \operatorname{lnE}_{\text {duexp }}+\beta_{2} \text { lnprim }_{t}+\beta_{3} \ln \text { Sec }_{t}+ \\
& \beta_{4} \ln G d p / \text { capita }_{t}+\beta_{5} \text { labourforce }_{t}+\beta_{6} g f c_{t}+\varepsilon_{t}
\end{aligned}
$$

Where Under-five mortality (UMR5) was used as the dependent variable for the two models. The other variables Educational Expenditure (Eduexp), Female Primary school enrolment ( prim), Female secondary enrollment (Sec), Female labour force participation (labourfroce) and Gross fixed capital (gfe) and national income per capita (Gdp/capita) were used as explanatory variables. All the Variable were transformed into logarithmic forms to solve the problem of non-linearity. $\beta^{\prime} S$ Represents the coefficient or the elasticity of the explanatory variables, $i^{\prime} s$ also denotes the individual countries in the panel FE and RE model 1 while $t^{\prime} s$ denotes the time periods.

\section{Results and Discussion}

This section presents and discusses the findings from the study following Eqns. (5) and (6). The study examined the major causes of the disparities in under-five mortality among African counties by emphasizing on female education as key predator of the disparities inter-alia some key control variables such as GDP per Capita, educational expenditure, female labour force participation, and gross fixed capital. Utilizing Eqn. (5), the panel $\mathrm{FE}$ and RE were models employed where the Hausman test judged the RE model as more appropriate as against the results from FE model even though the results from the two models are presented in Table 1.

Table 1. Estimated results from FE and RE analysis of the female education and other predicting factors of disparities of the under-five mortality

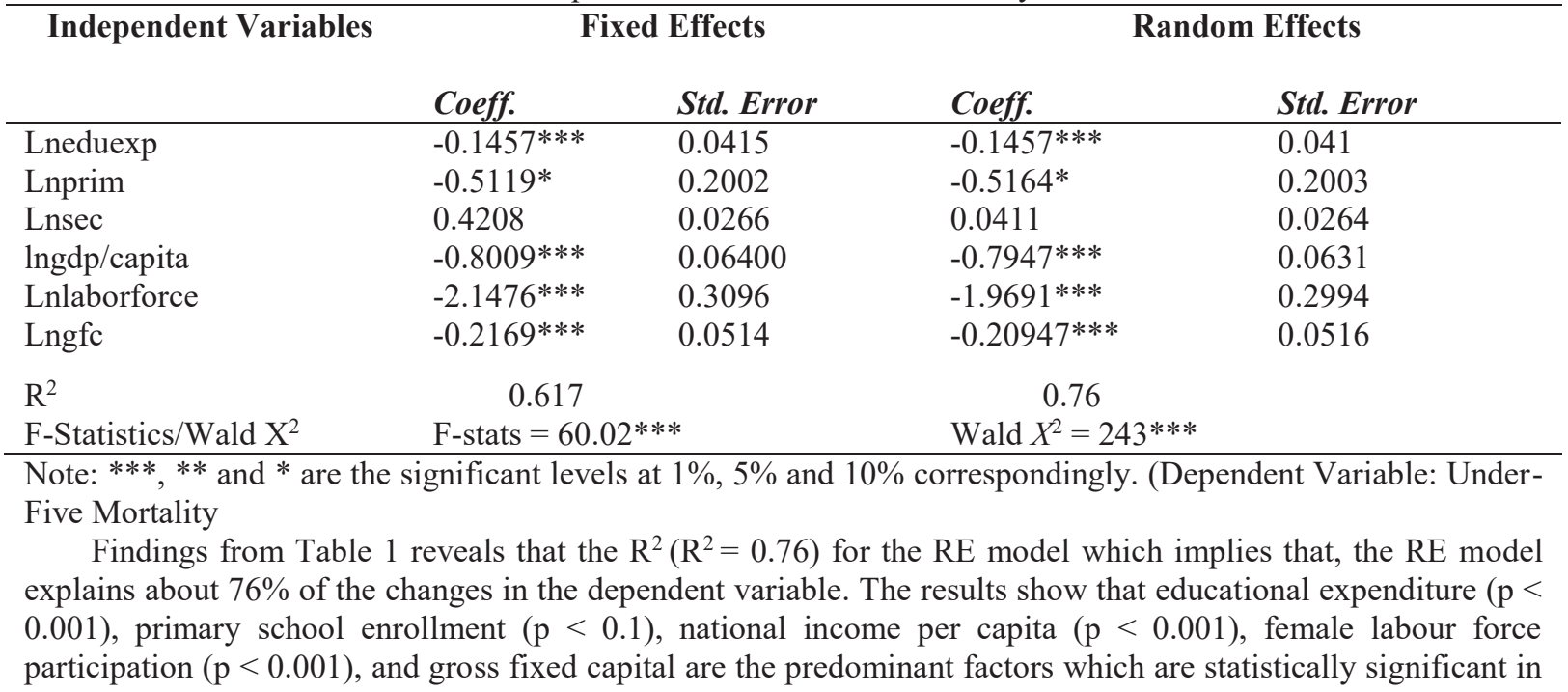


explaining the disparities in the under-five mortality among the regions selected for the study. All these factor have negative relationship with under-five mortality in that, any increase in these factors tend to reduce the incidence of under-five mortality rate. More intuitively, the results from Table 1 denotes that, a unit increase in educational expenditure reduced the incidence of under-five mortality by $0.146 \%$. An increase in female primary school enrollment by a unit also reduces the incidence of under-five mortality by $0.516 \%$. In the case GDP per capita used as proxy for economic growth, a unit increase in the economic growth minimizes the occurrence of under-five mortality by $0.795 \%$. The coefficient for female labour force participation indicates that, a unit increase in female labour force participation reduces the number of newly born babies less than 60 months by $1.691 \%$. The findings also shows that the gross fixed capital of the country also reduces the under-five mortality by $0.209 \%$. However, female secondary school was found to have no statistically significant impact on underfive mortality.

Table 2. Estimated results from OLS analysis of female education and other predicting factors of under-five mortality for individual countries

\begin{tabular}{|c|c|c|c|c|c|c|c|}
\hline country & Lneduexp & Lnprim & Lnsec & Lngdp/capita & Inlaborforce & lngfc & $\mathbf{R}^{2}$ \\
\hline \multirow[t]{2}{*}{ Ghana } & $-0.1097 * *$ & -0.3107 & $0.3646^{* *}$ & $-0.9294 * * *$ & $-0.663 * *$ & -0.0207 & 0.967 \\
\hline & $(0.0370)$ & $(0.4782)$ & $(0.1302)$ & $(0.1359)$ & $(1.6808)$ & $(0.0107)$ & \\
\hline \multirow[t]{2}{*}{ Kenya } & -0.02332 & 0.3157 & $-0.6034 * * *$ & $-1.3538 * * *$ & $-3.2543 * * *$ & $-0.2624 *$ & 0.98 \\
\hline & $(0.05059)$ & $(0.2668)$ & $(0.07513)$ & $(0.0736)$ & $(0.4786)$ & $(0.1306)$ & \\
\hline \multirow[t]{2}{*}{ Cameroon } & -0.0211 & -1.1426 & $-0.0613^{* *}$ & $-0.7316^{* * *}$ & $-13.0066 * * *$ & -0.0075 & 0.932 \\
\hline & $(0.0253)$ & $(0.8349)$ & $(0.0245)$ & $(0.10174)$ & $(0.2485)$ & $(0.1037)$ & \\
\hline \multirow[t]{2}{*}{ Egypt } & -0.0764 & $-1.7199 *$ & $-0.1528 * *$ & $-0.7137 * * *$ & $-1.2842 * * *$ & $0.2261 * *$ & 0.884 \\
\hline & $(0.11464)$ & $(0.9549)$ & $(0.05678)$ & $(0.0689)$ & $(0.2081)$ & $(0.07865)$ & \\
\hline \multirow[t]{2}{*}{ South Africa } & $-1.0544 * * *$ & 6.3072 & 0.1683 & $-1.7475 * * *$ & $-3.3170 * * *$ & $-0.1543^{* *}$ & 0.941 \\
\hline & $(0.3585)$ & $(4.2912)$ & $(0.1755)$ & $(0.3716)$ & $(0.90886)$ & 0.1947 ) & \\
\hline \multirow[t]{2}{*}{ Central African Republic } & $-0.0637^{*}$ & -0.448 & 0.008 & 0.133 & $-11.725^{* * *}$ & $-0.746^{* *}$ & 0.721 \\
\hline & $(0.030)$ & $(0.466)$ & $(0.0253)$ & $(0.1546)$ & $(2.253)$ & $(0.0230)$ & \\
\hline \multirow[t]{2}{*}{ Tunisia } & 0.05075 & 2.0762 & 0.00756 & $-1.5334 * * *$ & $-3.4513 * * *$ & $1.0745^{* * *}$ & 0.949 \\
\hline & $(0.0874)$ & (1.587) & $(0.0386)$ & $(0.1101)$ & $(0.5017)$ & $(0.1653)$ & \\
\hline \multirow[t]{2}{*}{ Ethiopia } & -0.0688 & $-0.4480 * *$ & -0.0426 & $-0.5641 * * *$ & $-7.4289 * * *$ & $-0.3759 * * *$ & 0.927 \\
\hline & $(0.5784)$ & $(0.210)$ & $(0.046)$ & $(0.0506)$ & $(1.2338)$ & $(0.10565)$ & \\
\hline \multirow[t]{2}{*}{ Burkina Faso } & -0.1005 & 0.07538 & -0.03597 & $-1.0753 * * *$ & $-1.0546 * * *$ & 0.1449 & 0.923 \\
\hline & $(0.2271)$ & $(0.8038)$ & $(0.0272)$ & $(0.3415)$ & $(0.1872)$ & $(0.03328)$ & \\
\hline
\end{tabular}

Note: values in parenthesis denote standard errors of the coefficients, $* * *, * *$ and $*$ are the significant levels at $1 \%, 5 \%$ and $10 \%$ correspondingly. (Dependent Variable: Under-Five Mortality

The results from Table 2 shows that, educational expenditure has a negative impact on under-five mortality in all the countries except Tunisia. This implies that, increase in educational expenditure reduces the incidence in under-five mortality in the countries such as Ghana $(\beta=-0.1097)$, Kenya $(\beta=-0.0233)$, Cameroon $(\beta=-0.0211)$, Egypt $(\beta=-0.764)$, South Africa $(\beta=-1.054)$, Central Africa Republic $(\beta=-0.0637)$, Ethiopia $(\beta=-0.069)$, and Burkina Faso $(\beta=-0.101)$. Again, the results show that, female primary school enrollment reduces under-five mortality among countries such as Ghana, Cameroon, Egypt, Central African Republic, and Ethiopia. In the case of female secondary school enrollment, the findings reveal that, under-five mortality is reduced as secondary school enrollment is increased and this is evident in countries such as Kenya, Cameroon, Egypt and Ethiopia. The results from the table also show that, GDP per capita, labour force participation had significant impact on reducing the under-five mortality in all the countries even though the magnitude of the impact differs from country to country depending on the level of economic growth and female labour force participations. The results indicate that a unit increase in GDP per capita which is a proxy for economic growth reduces the under-five mortality in Ghana $(0.98 \%)$, Kenya $(1.358 \%)$, Cameroon $(0.734 \%)$, and Egypt (0.714\%), South Africa (1.748\%), Tunisia (1.53\%) Ethiopia (0.564\%) and Burkina Faso (1.075\%). In the case of Central African Republic, GDP per Capita did not have statistically significant impact on under-five mortality. The findings again indicate that, female labour force participation has a greater impact on reducing the under-five mortality rate. Results from Table 2 depicts that, a unit increase in the female labour force participation decrease the under-five mortality in all the countries and this impact is greater in Cameroon (13.01\%), Central African Republic (11.72\%), Ethiopia (7.43\%), South Africa (3.31\%), Kenya (3.25\%), while Ghana experienced the least impact of $0.66 \%$. The gross fixed capital which were also set as control variables also showed significant negative impact on under-five mortality among the countries. The findings show that, educational expenditure, primary education school enrolment have a great impact on reducing the under-five mortality compared with female secondary education enrollment. It gives a clue that, these countries must build a strong foundation to increase the enrolment in these primary education while placing equal attention on secondary education. This agrees with several studies which stressed that, improving female education reduces 
under-five mortality (Okuonzi \& Birungi, 2000). The findings also confirms that of (Wagstaff et al., 2004) who also concluded that, children born to uneducated mothers have a higher risk of dying that babied from educated mothers. Female labour force appeared to also have greater impact on reducing the under-five mortality Increasing educational expenditures particularly on female education could help reduce the incidence of child death in Africa and among other developing countries. These findings are in line with studies by (Braveman et al., 2005) who argued that, difference in national income per capita contribute greatly to the regional disparities in under five mortality. As countries high income per capita achieve minimum child deaths as compared to countries with lower income per capita. The findings support that, educating our women has a great impact on controlling the population growth, child mortality and reducing under-five mortality. Female labour force participation also contribute significantly to reducing under-five mortality. The more these females are engage in economic activities to earn some form of income they obtain the financial abilities to meet the basic nutritional diet requirement of their children and helps to minimize their risk of dying or becoming malnourished (AbuGhaida \& Klasen, 2004). This study provides a strong evidence that, female education, female labour force participation and income per capita be given the much attention to be able to minimize the rate of child death among African countries and other developing countries in the World.

\section{Conclusions and Policy Recommendations}

The study examined the key predictors of the disparities in under-five mortality in some selected African countries using a panel data obtained from the World Bank's World Development indicator (WDI) covering a period of 2000-2017. The panel random effect model was utilized to estimate the polled data analysis for all the countries selected, while the time series multiple regression analyses were also used to estimate the predictors of the disparities of the under-five mortalities in the individual countries. The results revealed that, female primary school enrolment, female labour force participation, GDP per capita as proxy for economic growth were statistically significant and predominately strong predators of the disparities in the rate of under-five mortality among the countries. The study recommends that, health policies to reduce child mortality should be designed inter-alia in with educational policies since education makes individual more conscious about their health and a healthy mind is a sound mind for learning. Policy direction on the essence to prioritize female education with high political will and commitment especially towards accomplishing low child deaths and moving Africa from our global top position as a leading continent in child death worldwide.

Adequate resources should be directed towards female education and much equal attention and investment should be given to all levels of female education. Some countries invest more in secondary education while neglecting the primary and tertiary education. On the other hand, some countries pay more attention to the primary education or equal attention to the secondary education. Moreover, every level of female education is equally important in contributing to minimizing under-five mortality and socio economic development. Again, the females should be given more scholarships to be able to promote their education. Furthermore, the government and NGO's should help to minimize the cost of educating our females since they play a major role in controlling the world population, family welfare among others. Measures should be taken by African leaders and educational policy makers to control the rates of school drop outs, and child trafficking which impede the successful achievement of female education among African countries.

\section{Acknowledgements}

The authors would like to acknowledge Charles Dwumfour Osei and Desmond Appiah (Ph. D. Candidates of Jiangsu University) for their valuable contributions in diverse ways.

\section{References}

Abu-Ghaida, D., \& Klasen, S. (2004). The costs of missing the Millennium Development Goal on gender equity. World Development, 32(7), 1075-1107.

Ainsworth, M., Beegle, K., \& Nyamete, A. (1996). The impact of women's schooling on fertility and contraceptive use: A study of fourteen sub-Saharan African countries. The World Bank Economic Review, 10(1), 85-122.

Ashraf, Q. H., Weil, D. N., \& Wilde, J. (2013). The effect of fertility reduction on economic growth. Population and development review, 39(1), 97-130.

Barro, R. J., \& Lee, J.-W. (2010). A New Data Set of Educational Attainment in the World, 1950-2010. NBER Working Paper No. 15902. National Bureau of Economic Research.

Barro, R. J., \& Lee, J. W. (2013). A new data set of educational attainment in the world, 1950-2010. Journal of development economics, 104, 184-198.

Bhutta, Z. A., Chopra, M., Axelson, H., Berman, P., Boerma, T., Bryce, J., . . Daelmans, B. (2010). Countdown to 2015 decade report (2000-10): taking stock of maternal, newborn, and child survival. The lancet, 375(9730), 2032-2044. 
Bloom, D. E., Canning, D., \& Chan, K. (2006). Higher education and economic development in Africa (Vol. 102): World Bank Washington, DC.

Braveman, P. A., Cubbin, C., Egerter, S., Chideya, S., Marchi, K. S., Metzler, M., \& Posner, S. (2005). Socioeconomic status in health research: one size does not fit all. Jama, 294(22), 2879-2888.

El Alaoui, A. (2015). Impact of women's education on the economic growth: An empirical analysis applied to Morocco, Algeria, Tunisia, and Egypt.

Gava, D., \& Duada, A. (2013). The Poor, Poverty, and Spiritual Growth. The WATS Journal: An Online Journal from West Africa Theological Seminary, 1(1), 4.

Klasen, S. (2002). Low schooling for girls, slower growth for all? Cross - country evidence on the effect of gender inequality in education on economic development. The World Bank Economic Review, 16(3), 345373.

Mujahid, N., \& uz Zafar, N. (2012). Economic growth-female labour force participation nexus: an empirical evidence for Pakistan. The Pakistan Development Review, 565-585.

Office, W. B. V. C., \& Vietnam, C. G. f. (1999). Vietnam, attacking poverty: World Bank in Vietnam.

Okuonzi, S. A., \& Birungi, H. (2000). Are lessons from the education sector applicable to health care reforms? The case of Uganda. The International journal of health planning and management, 15(3), 201-219.

Shirahase, S. (2000). Women's increased higher education and the declining fertility rate in Japan. Review of population and social policy, 9(2000), 47-63.

Unicef. (2018). Statistical tables. State of the World's Children, 146-205.

Wagstaff, A., Bustreo, F., Bryce, J., Claeson, M., Health, W. W. B. C., \& Group, P. W. (2004). Child health: reaching the poor. American journal of public health, 94(5), 726-736. 